\title{
Discharge to Primary Care for Survivorship Follow-Up: How Are Patients With Early-Stage Breast Cancer Faring?
}

\author{
Cindy Railton, MN, RN, ACNPa; Sasha Lupichuk, MD; Jennifer McCormick, MSc ${ }^{\mathrm{b}, \mathrm{c}}$; Lihong Zhong, MSc ${ }^{\mathrm{b}, \mathrm{c}}$; \\ Jenny Jaeeun Ko, MDa; Barbara Walley, MDa; Anil A. Joy, MD'; and Janine Giese-Davis, $\mathrm{PhD}^{\mathrm{b}, \mathrm{c}}$
}

\section{Abstract}

Purpose: Oncology centers in public health systems often transfer routine follow-up of patients with early-stage breast cancer (BC) to primary care physicians because of the increasing numbers of survivors and evidence supporting the safety of this practice. After transfer of care, it is unknown how BC survivors fare with treatment and surveillance goals, and whether they have unmet needs for access to specialist care. This study conducted in a sample of women in Alberta, Canada, examined adherence with follow-up guidelines, symptoms, and need for a telephone-based survivorship clinic. Methods: Through the Alberta Cancer Registry, we randomly invited women with stage I-III invasive BC ( $N=960)$ to participate. Of those, 272 responded, and 240 consented to a structured telephone interview and chart review. Results: Women adhered well to follow-up guidelines for mammogram, but less so for clinical examination and endocrine therapy (ET). However, most patients reported ongoing bothersome symptoms, which tended to be higher in those not on ET. More than one-third of patients reported ongoing needs (managing weight, side effects, exercise adherence, and psychosocial health). Younger, fatigued or depressed, nonurban women not on ET reported the most need for a telephone clinic. Conclusions: Adherence with follow-up goals (examination, mammography, ET) was better than expected. Despite this, interest in a telephone survivorship clinic was high. Perceived needs included symptom management plus support for lifestyle behavior change. Medical follow-up needs might be well-met by discharge to primary care. However, high levels of ongoing symptoms and psychosocial needs would suggest that telephone-based survivorship clinics, psychosocial and exercise interventions, or transition programs might benefit the survivorship experience of patients with BC. (J Natl Compr Canc Netw 2015;13:762-771)

\section{Introduction}

Women diagnosed with breast cancer (BC) in developed countries are living longer because of earlier diagnosis and more effective therapies leading to high numbers of survivors for cancer centers to follow. ${ }^{1,2}$ In 2013, new BC diagnoses in the United States totaled $234,580^{3}$ and in Canada were $24,000 .^{2}$ Oncologists will treat more than $90 \%$ of these BCs with curative intent if the cancer is localized to the breast or regional lymph nodes. Treatments include surgery, radiation, chemotherapy, and, if the tumor is estrogen receptor-positive,

From the aDepartment of Oncology, University of Calgary, Tom Baker Cancer Centre; 'bepartment of Oncology, Division of Psychosocial Oncology, University of Calgary; and 'Psychosocial Resources, Tom Baker Cancer Centre, Calgary, Alberta, Canada, and the dDepartment of Oncology, University of Alberta, Cross Cancer Institute, Edmonton, Alberta, Canada.

Submitted October 4, 2014; accepted for publication April 2, 2015.

The authors have disclosed that they have no financial interests, arrangements, affiliations, or commercial interests with the manufacturers of any products discussed in this article or their competitors.

This study received funding from the Canadian Breast Cancer FoundationNorthwest Territories. In addition, funding for Dr. Giese-Davis' salary endocrine therapies (ET) for at least 5 years. Clinical practice guidelines for follow-up care recommend periodic physical examination and annual mammography in early-stage $\mathrm{BC}$ survivors when there is remaining breast tissue. ${ }^{4-6}$ Some guidelines also address adherence to ET, ongoing management of treatment-related toxicity, psychosocial health, sexual health/fertility, body weight, and physical activity, ${ }^{4,6,7}$ because adherence to lifestyle guidelines may result in survival benefit. ${ }^{8,9}$

Although the optimal follow-up care model is unknown, in many publically funded health systems in both the United States and Canada, oncologists now support comes from Alberta Health Services, and The Enbridge Chair for Psychosocial Oncology Research held by Linda E. Carlson.

Portions of these results were presented at the ASCO 2013 Annual Conference, Chicago, IL, May 31-June 4, 2013; the annual Alberta Provincial Breast Tumor Group meeting, Kananaskis Country, AB, March 8-10, 2013; the 2012 Canadian Association of Psychosocial Oncology (CAPO) Conference, Vancouver, BC, April 25-28, 2012; and the 2011 Canadian Cancer Research Conference, Toronto, ON, November 27-30, 2011.

Correspondence: Janine Giese-Davis, PhD, Department of Oncology, Faculty of Medicine, University of Calgary, 3330 Hospital Drive, NW, Calgary, Alberta, T2N 4N1, Canada. E-mail: jgieseda@ucalgary.ca 
How Are Discharged BC Survivors Faring?

transfer routine posttreatment follow-up care of patients with early-stage BC back to primary care providers (PCPs), which include gynecologists in the United States. ${ }^{10,11}$ Follow-up guidelines address this transfer of care to the $\mathrm{PCP},{ }^{4-7}$ and survivorship guidelines and strategies are emerging to help patients, oncology providers, and PCPs with these transitions. ${ }^{7,12}$ This shift in care model followed successful randomized trials demonstrating comparable incidence of recurrence-related serious events, economic superiority, comparable time-to-recurrence diagnosis, patient satisfaction, and quality of life (QOL) for PCP follow-up. ${ }^{13-17}$ Although surveillance mammography and antiestrogen treatment adherence improve survival, ${ }^{18-29}$ published reports of adherence levels in PCP care are rare. Likewise, unmet survivorship needs are often high, ${ }^{30,31}$ and reports of unmet survivorship needs for PCP care are few. ${ }^{32}$

For many patients with $\mathrm{BC}$, optimal posttreatment care requires access to services that help sustain QOL. ${ }^{1,33}$ Subpopulations might differentially benefit from PCP versus oncology-provider follow-up for common ET side effects and survivorship needs. Younger women ${ }^{33}$ and those living in rural settings, ${ }^{34}$ on ET plans, ${ }^{35}$ closer to time of diagnosis, and discharged from cancer care cr,37 $^{36}$ ften report higher posttreatment needs. Studies suggest that oncology nurse or nurse practitioner (NP)-led telephone clinics can provide a link between patients, PCPs, and oncologists. ${ }^{38,39}$ Nurses can either address lifestyle and psychosocial concerns or refer patients..$^{40}$ In this cross-sectional study in a Canadian public health system that discharges to PCPs for follow-up, we examined adherence and perceived need for help with follow-up goals, and interest in a telephone-based survivorship clinic. We hypothesized that those at greater risk, younger, nonurban, taking ET, with shorter times since diagnosis, and transferred from cancer center care would report a significantly greater projected use of a telephone clinic.

\section{Methods}

\section{Participants}

Eligible Alberta women were English-speaking, were 18 years of age or older, had stage I-III invasive BC diagnosed June 2006-September 2009, and were treated through tertiary cancer centers. Women excluded had recurrent or metastatic BC, or their diag- nosis date fell outside the study window. The Alberta Cancer Registry (ACR) randomly sampled eligible participants, oversampling younger, nonurban women further from their date of diagnosis to ensure representation. ACR then mailed study invitations including consent forms. If interested, women returned a signed consent and the research assistant called them to answer questions and schedule an interview. For those not responding, ACR mailed a reminder postcard 2 weeks later. The Calgary Health Region Research Ethics Board and the Alberta Cancer Research Ethics Committee approved the procedures.

Of 960 potentially eligible participants receiving invitation letters from ACR, 272 consented $(28.3 \%)$. Of these, 240 completed a structured telephone interview, had usable data from chart review, and were included. Reasons for the exclusion of 32 participants varied from unsuccessful contact $(n=10)$, ineligibility $(n=15)$, interviewed but discovered to be ineligible $(n=5)$, and withdrawal $(n=2)$.

\section{Procedure and Measures}

Researchers extracted from chart review patient demographics, tumor characteristics, treatment (surgical, radiation, chemotherapy, and ET plan), discharge status, and cancer center visits postdischarge. For women on an ET plan, researchers also extracted medication dispensing information from cancer center pharmacy databases.

Interview: The research team, including breast oncologists, a breast NP, and psychologists, designed the structured interview using consensus agreement. The interview included the following categories (Appendix 1; located at the end of this article): current bothersome symptoms; types of breast surgeries; adherence to ET, medical, and lifestyle follow-up guidelines; and desire for follow-up care assistance. Because PCPs separately held most women's current records, we were unable to verify selfreported clinical examination and mammography. At the end of the interview, the research assistant asked, "Now I would like for you to think back over time since you finished your treatment. If you had the option to speak on the phone with a medical professional in a BC survivorship clinic, would you have used it?" We refer to this throughout the paper as the "hypothetical BC telephone clinic" (HTC).

Adherence With Guidelines: We measured frequency of self-reported prior-year clinical examina- 
tion, mammography, body mass index (BMI), exercise, and alcohol use. To estimate adherence with ET guidelines, we measured current use based on self-report and pharmacy records. From pharmacy records, we measured nonadherence (filled prescriptions covered $\leq 80 \%$ of potential time on therapy), nonpersistence (continuous period $>6$ months when no prescription was filled), and frequency and timing of planned switches from tamoxifen to aromatase inhibitors (AIs).

\section{Analysis}

To summarize demographic, chart review, pharmacy, and interview data, we used descriptive statistics, SAS 9.3, and 2-tailed tests. Using chi-square and Fisher exact tests, we compared PCP versus cancer center care for patients' demographic and medical details. Because both care provider and estrogen status can affect outcomes, we examined current symptoms, need for assistance with follow-up goals, and adherence using logistic regression with 2 factors: care provider (cancer center vs PCP) and ET plan (yes vs no). With logistic regression, we examined what factors predicted whether women reported that they would have used an HTC. Eight relatively noncollinear independent predictors included (1) age at interview ( $\geq 55$ vs $<55$ years); (2) residence (urban/ nonurban); (3) ET plan (yes/no); current symptoms, including (4) fatigue, (5) hot flashes, and (6) vaginal dryness (yes/no); (7) time since diagnosis (months); and (8) discharge status (cancer center/PCP followup). We examined whether we could include depression, but it was collinear with residence and fatigue. Using the same predictors, but replacing residence and fatigue with depression, we explored the impact of depression on HTC use.

\section{Results}

Of the 240 Alberta women who participated in this study, half $(46.7 \%)$ were younger than 50 years, one-third $(32.5 \%)$ were more than 48 months from diagnosis, and approximately half $(52.9 \%)$ lived in nonurban settings, indicating that our oversampling was effective. Most participants had stage I or II disease $(89.2 \%)$, half underwent breast-conserving surgery $(49.6 \%)$, $72.9 \%$ had radiation, and $62.1 \%$ received chemotherapy. A total of $80 \%$ of participants had hormone-responsive BC, and for $97.5 \%$ of these individuals, oncologists prescribed an ET plan.
Women not on an ET plan were significantly older $(P=.04)$. To examine possible sample bias because of our $28.3 \%$ response rate, we compared age and cancer stage (from ACR) between those completing our study and aggregated nonresponders. We found no significant differences (completers/nonresponders: age, $P=.12$; stage $\%, P=.38)$.

At interview, oncologists had transferred $\mathrm{BC}$ surveillance from cancer center to PCP for $68.8 \%$ of participants (Table 1). Those not transferred were significantly younger at diagnosis $(P=.005)$ and had a later disease stage $(P=.01)$. Of those transferred, $80.0 \%$ identified their PCP as their follow-up provider, and only $2.4 \%$ had no physician/nurse surveillance. Among those transferred, 23.6\% had returned to the cancer center for at least one visit (from chart review): most for a planned switch from tamoxifen to AI $(60.5 \%)$, but nearly $40 \%$ for other reasons (unplanned switch to AI, relapse concerns, other).

Overall, bothersome symptoms were common (Table 2), and included fatigue $(67.5 \%)$, perceived memory loss (59.6\%), and symptoms of estrogen deprivation (eg, hot flashes, 64.2\%). For most symptoms, more than $50 \%$ of participants reported ongoing problems. Those being followed up by their PCP reported significantly less fatigue. Those not on an ET plan reported significantly more paresthesias (not taxane-related) but fewer hot flashes.

We examined adherence with guidelines for clinical examination (breast/chest/lymph node examination by a health care professional) and mammography in the previous year (all tests in Table 3). Among participants, $88.6 \%$ reported having an examination, $11.2 \%$ did not recall having one, and $1.7 \%$ were unsure. Although the number of participants having an examination was high overall, those being followed up by their PCP reported significantly fewer examinations $(85.6 \%$ vs $95.7 \%$; $P=.04$ ). Among survivors with remaining breast tissue, $97.1 \%$ reported having a mammogram. We examined survivors' adherence with self-reported lifestyle guidelines. Approximately 75\% reported an elevated BMI, yet most women followed weekly behavioral guidelines: per week, $62.1 \%$ reported at least 2.5 hours of moderate to vigorous exercise, and $92.5 \%$ reported 7 or fewer servings of alcohol.

We examined adherence with ET based on selfreport and pharmacy records (numbers reported in Table 4). A total of $95.4 \%$ of women with an ET 
How Are Discharged BC Survivors Faring?

\begin{tabular}{|c|c|c|c|c|c|c|c|}
\hline \multirow[b]{3}{*}{ Characteristics } & \multirow{2}{*}{\multicolumn{2}{|c|}{ Total }} & \multicolumn{4}{|c|}{ Cancer Care Follow-Up } & \multirow[b]{3}{*}{$\chi^{2}$ ( $P$ Value) } \\
\hline & & & \multicolumn{2}{|c|}{$\begin{array}{l}\text { Cancer Center } \\
(n=69)\end{array}$} & \multicolumn{2}{|c|}{$\begin{array}{c}\text { PCP - Community } \\
(n=171) \\
\end{array}$} & \\
\hline & $\mathbf{n}$ & $\%$ & $\mathbf{n}$ & $\%$ & $\mathbf{n}$ & $\%$ & \\
\hline \multicolumn{8}{|l|}{ Age at diagnosis } \\
\hline$<50$ y & 112 & 46.7 & 42 & 60.9 & 70 & 40.9 & $7.85(.01)$ \\
\hline$\geq 50 \mathrm{y}$ & 128 & 53.3 & 27 & 39.1 & 101 & 59.1 & \\
\hline \multicolumn{8}{|l|}{ Residence } \\
\hline Urban & 113 & 47.1 & 37 & 53.6 & 76 & 44.4 & $1.66(.20)$ \\
\hline Nonurban & 127 & 52.9 & 32 & 46.4 & 95 & 55.6 & \\
\hline \multicolumn{8}{|l|}{ Time from diagnosis (mo) } \\
\hline $12-24$ & 11 & 4.6 & 6 & 8.7 & 5 & 2.9 & $6.91(.07)$ \\
\hline $25-36$ & 61 & 25.4 & 22 & 31.9 & 39 & 22.8 & \\
\hline $37-48$ & 89 & 37.1 & 23 & 33.3 & 66 & 38.6 & \\
\hline$>48$ & 79 & 32.9 & 18 & 26.1 & 61 & 35.7 & \\
\hline \multicolumn{8}{|l|}{ Stage } \\
\hline I & 113 & 47.1 & 26 & 37.7 & 87 & 50.9 & $9.81(.01)$ \\
\hline II & 101 & 42.1 & 29 & 42.0 & 72 & 42.1 & \\
\hline III & 26 & 10.8 & 14 & 20.3 & 12 & 7.0 & \\
\hline \multicolumn{8}{|l|}{ ER status } \\
\hline Positive & 198 & 82.5 & 58 & 84.1 & 140 & 81.9 & $0.16(.69)$ \\
\hline Negative & 42 & 17.5 & 11 & 15.9 & 31 & 18.1 & \\
\hline \multicolumn{8}{|l|}{ Breast surgery } \\
\hline Conservation & 119 & 49.6 & 30 & 43.5 & 89 & 52.1 & $1.44(.23)$ \\
\hline Mastectomy & 121 & 50.4 & 39 & 56.5 & 82 & 48.0 & \\
\hline \multicolumn{8}{|l|}{ Axillary management } \\
\hline SN only & 126 & 52.5 & 31 & 44.9 & 95 & 55.6 & $2.77(.25)$ \\
\hline Axillary dissection $+/-\mathrm{SN}$ & 113 & 47.1 & 38 & 55.1 & 75 & 43.9 & \\
\hline None & 1 & 0.4 & 0 & 0 & 1 & 0.6 & \\
\hline \multicolumn{8}{|l|}{ Chemotherapy } \\
\hline Anthracycline only & 52 & 21.7 & 13 & 18.8 & 39 & 22.8 & $4.38(.22)$ \\
\hline Taxane only & 43 & 17.9 & 16 & 23.2 & 27 & 15.8 & \\
\hline Anthracycline + taxane & 54 & 22.5 & 19 & 27.5 & 35 & 20.5 & \\
\hline None & 91 & 37.9 & 21 & 30.4 & 70 & 40.9 & \\
\hline \multicolumn{8}{|l|}{ Radiation } \\
\hline Yes & 175 & 72.9 & 53 & 76.8 & 122 & 71.4 & $0.74(.39)$ \\
\hline No & 65 & 27.1 & 16 & 23.2 & 49 & 28.7 & \\
\hline \multicolumn{8}{|l|}{ Age at interview } \\
\hline$<55$ y & 119 & 49.6 & 43 & 62.3 & 76 & 44.4 & $6.28(.01)$ \\
\hline$\geq 55 \mathrm{y}$ & 121 & 50.4 & 26 & 37.7 & 95 & 55.6 & \\
\hline \multicolumn{8}{|l|}{ Endocrine therapy plan } \\
\hline Yes & 185 & 77.1 & 53 & 76.8 & 132 & 77.2 & $0.004(.95)$ \\
\hline No & 55 & 22.9 & 16 & 23.2 & 39 & 22.8 & \\
\hline $\begin{array}{l}\text { Median time from diagnosis } \\
\text { to discharge from cancer } \\
\text { center, mo (range) }\end{array}$ & 165 & $\begin{array}{l}11.4 \\
(1.8-42.8)\end{array}$ & 9 & $\begin{array}{l}12.4 \\
(7.3-29.7)\end{array}$ & 156 & $\begin{array}{l}11.3 \\
(1.8-42.0)\end{array}$ & $0.93(.35)$ \\
\hline
\end{tabular}

Abbreviation: ER, estrogen receptor; $\mathrm{PCP}$, primary care provider; SN, sentinel node.

Percentages and chi-square/Wilcoxson (rank sums) test results.

plan had a current prescription for ET according to pharmacy records; however, only $82.3 \%$ reported current use. Further interrogation of pharmacy records showed that $6.5 \%$ had prescriptions covering less than $80 \%$ of their time on treatment ("nonadherent"), and $16.2 \%$ had a lapse in prescriptions over a continuous 6-month period ("nonpersistent"). For $39.4 \%$, the ET plan included a switch to AI. At interview, $48.7 \%$ of those had undergone this switch ( mean $=23.8$ months from initiation of tamoxifen to switch). Additionally, for women on an AI at the time of the interview, $58.46 \%$ reported ever having 


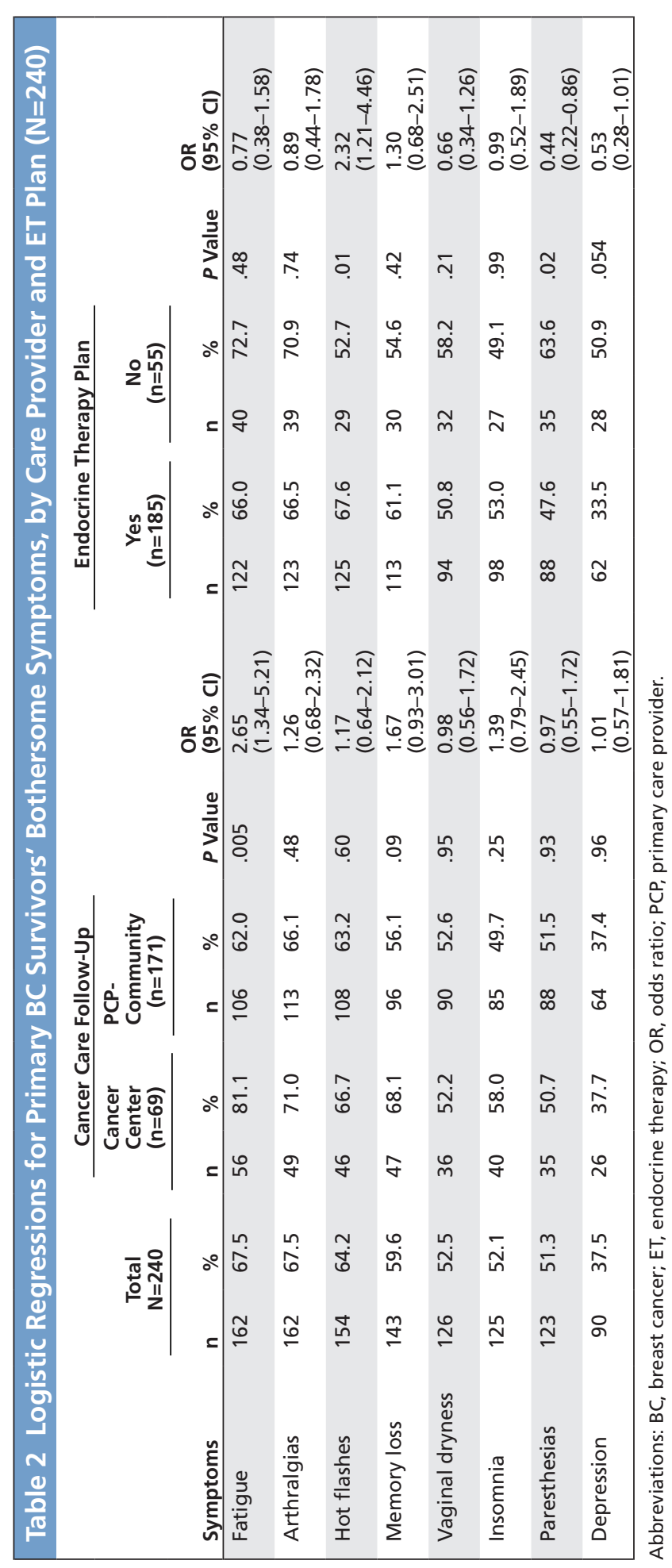

a bone mineral density (BMD) test, and $33.85 \%$ reported having a BMD test within the prior year. Our follow-up guideline and discharge letter recommend baseline BMD testing with AI prescriptions and regular BMD scans with follow-up/treatment according to the Osteoporosis Canadian Guidelines.

Self-reported need for assistance with follow-up (Table 5) showed that, although few women needed help accessing clinical examinations $(14.6 \%)$ or mammography $(6.7 \%)$, they reported higher needs for side-effect management and achieving lifestyle, psychosocial, and sexual-health goals $(21.7 \%$ $35.8 \%)$. Those not on an ET plan reported significantly more need for assistance with exercise goals.

Women reported that, if an HTC was available, most $(71.7 \%)$ would have used it, $22.9 \%$ would not have, with $5.4 \%$ unsure. Results of logistic regression (Table 6), demonstrated that younger women $(P<.0001)$, residing in nonurban settings $(P=.05)$, without an ET plan $(P=.0007)$, and reporting fatigue $(P=.004)$ were significantly more likely to say they would use an HTC. We could not demonstrate that discharge to PCP disproportionally predicted projected use.

We explored the effects of depression, which was collinear with residence (higher depression in nonurban settings [62.2\% vs $\left.37.8 \% ; \chi^{2}=5.0, P=.03\right]$ ), and fatigue (patients reporting depression also reported fatigue [84.4\% vs $\left.\left.15.6 \%, \chi^{2}=18.85, P<.0001\right]\right)$. Removing residence and fatigue and substituting depression duplicated results, with the addition that greater depression significantly predicted greater projected use (odds ratio [OR], 5.13 [2.31-11.38], $P<.0001)$.

\section{Discussion}

This study explored how early-stage BC survivors in Alberta, Canada, were faring at least 1-year postdiagnosis, most of whom oncologists had transferred to PCP follow-up. Factors examined included PCP adherence to clinical and lifestyle guidelines, continuing use of cancer centers, ongoing bothersome symptoms, and perceived need for assistance with follow-up goals. We found that adherence to guideline recommendations was high for mammography and examinations, but for examinations was significantly lower than cancer center care. Adherence to ET was higher than some previous studies, though nonadherent and nonpersistent use totaled $22.7 \%$. Current transfer of care from cancer center to PCP follow-up, Alberta's standard practice, resulted in adherence to medical follow-up guidelines similar to literature reports. 


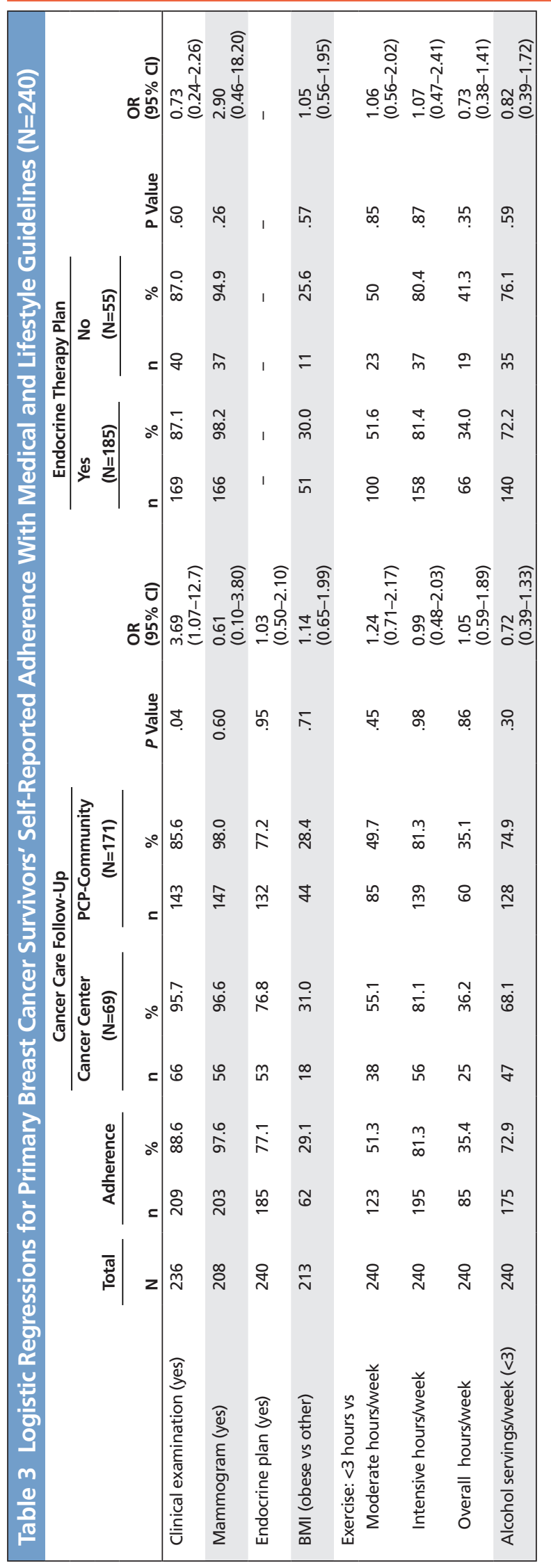

Follow-up guidelines suggest periodic physical examination and annual mammography because locoregional recurrence and new primary $\mathrm{BC}$ is potentially curable. ${ }^{4-7}$ Similarly, a retrospective Canadian study found that most women (>97\%) adhered annually to examinations but only $66 \%$ to mammography according to insurance records. ${ }^{41}$ Their lower mammography rate $(66 \%$ vs our $97.1 \%)$ occurred in a province with both PCP and oncology follow-up; hence, their lack of clear assignment of surveillance provider might have reduced adherence, ${ }^{13}$ whereas our clear assignment might have improved adherence. Our study tentatively supports clear transfer of care to PCP for mammography and examination follow-up.

Adjuvant ET improves disease-free and overall survival for hormone-responsive BC..$^{24,42-44}$ Followup guidelines are beginning to address adherence to ET, ${ }^{7}$ and recently, Alberta's revised discharge letter for BC survivors includes recommendations to assess and encourage adherence to ET (Appendix 2; located at the end of this article). In the current study, ET adherence based on self-report and pharmacy records was higher than reported in previous studies, and switches to an AI occurred appropriately. However, opportunity for improvement is comparable to findings reported in previous randomized trials, in which $23 \%$ to $28 \%$ patients prematurely discontinued ET therapy $^{27}$ (similar to our 22\%). Alberta's publicly funded cancer center pharmacies dispense all adjuvant ET. PCPs receive directions for prescribing ongoing ET in a formal discharge letter (although survivors discuss ET switches at cancer centers). Increasing out-of-pocket costs aside, the most common factors associated with discontinuation of or nonadherence to ET include extremes of age and side effects. ${ }^{28,29}$ In our study, $35 \%$ of all women reported unmet needs for assistance with side effects that might undermine adherence.

We found that most women $(>50 \%)$ reported ongoing fatigue, joint pain, hot flashes, memory loss, vaginal dryness, insomnia, paresthesias, and depression. Women not on ET reported significantly more paresthesias but fewer hot flashes. Additionally, 20\% to $35 \%$ reported need for assistance beyond that offered by current providers for managing body weight and side effects, achieving exercise goals, and sustaining psychosocial and sexual health. Lastly, 71\% reported that they would have used an HTC if it ex- 
Railton et al

\begin{tabular}{|c|c|c|}
\hline & Pharmacy & Self-Report \\
\hline Current ET & 185/193 (95.8\%) & 159/193 (82.3\%) \\
\hline Nonadherent & $12 / 185(6.5 \%)$ & \\
\hline Nonpersistent & $30 / 185(16.2 \%)$ & \\
\hline $\begin{array}{l}\text { Planned Al switch } \\
(76 / 193)\end{array}$ & $37 / 76(48.7 \%)$ & \\
\hline $\begin{array}{l}\text { Mean number of } \\
\text { months to planned Al } \\
\text { switch (range) }\end{array}$ & $23.8(1.2-43.7)$ & \\
\hline
\end{tabular}

Abbreviations: Al, aromatase inhibitor; ET, endocrine therapy.

isted, although our question did not specify type of clinic or type of oncology specialist. These numbers indicate that even if PCP follow-up meets medical guidelines, many $\mathrm{BC}$ survivorship needs may remain unmet.

Our findings confirmed our predictions that younger, more fatigued women living in nonurban settings projected greater use of an HTC, and found that depression was proxy to fatigue and nonurban location. We could not demonstrate that hot flashes, vaginal dryness, discharge from cancer center, or time since diagnosis significantly predicted telephone clinic use. Women with no ET plan endorsed HTC use more often, contrary to our prediction. These women may struggle with their often less-favorable prognosis $^{45}$ or their transfer of care. They were not significantly less likely to have visited the oncology clinic than those on an ET plan (chi-square, 0.02; $P=.89$ ).

A telephone clinic might work well for higherneeds populations in which gaps in service occur or individual factors interfere. For instance, younger women may struggle with finding time for programs or clinic visits while raising young families. ${ }^{33}$ Psycho-biological issues in depression and fatigue can negatively impact ability to adhere to treatment guidelines, return to work, and access timely care. ${ }^{46,47}$ Nonurban women likely experience greater needs for survivorship services ${ }^{34}$ and rarely have access to local psychosocial treatment for depression. Although Alberta's publicly funded psychosocial oncology and emerging physical activity programs exist in tertiary centers, nonurban locations lack resources to provide these supports effectively. A cancer center telephone clinic could fill some gaps by providing answers to questions, encouraging adherence, and referring women to needed survivorship services.

This integrated shared care may protect patients while reducing health care costs. ${ }^{48,49} \mathrm{BC}$ survivors are reassured by oncologist visits but express comfort with shared care from PCPs or NPs. ${ }^{32,50}$ PCPs believe that survivors prefer oncologist follow-up, ${ }^{51}$ and their willingness to assume survivor care and confidence to do so varies. ${ }^{48,51,52}$ Shared-care models rely on exemplary communication. Although care plans and discharge letters are becoming standard for communi-

Table 5 Logistic Regressions for Primary Breast Cancer Survivors' Perceived Need for Assistance With Follow-Up Goals, by Care Provider and Endocrine Therapy Plan ( $\mathrm{N}=240)$

\begin{tabular}{|c|c|c|c|c|c|c|c|c|c|c|c|c|c|c|}
\hline \multirow[b]{3}{*}{ Perceived Needs } & & & \multicolumn{4}{|c|}{ Cancer Care Follow-Up } & \multirow[b]{3}{*}{$\begin{array}{l}P \\
\text { Value } \\
\end{array}$} & \multirow[b]{3}{*}{$\begin{array}{l}\text { OR } \\
(95 \% \mathrm{Cl}) \\
\end{array}$} & \multicolumn{4}{|c|}{ Endocrine Therapy Plan } & \multirow[b]{3}{*}{$P$ Value } & \multirow[b]{3}{*}{$\begin{array}{l}\text { OR } \\
(95 \% \mathrm{Cl})\end{array}$} \\
\hline & \multicolumn{2}{|c|}{$\begin{array}{l}\text { Total } \\
\mathrm{N}=240\end{array}$} & \multicolumn{2}{|c|}{$\begin{array}{l}\text { Cancer } \\
\text { Center } \\
(\mathrm{n}=69) \\
\end{array}$} & \multicolumn{2}{|c|}{$\begin{array}{l}\begin{array}{l}\text { PCP- } \\
\text { Community } \\
(n=171)\end{array} \\
\end{array}$} & & & \multicolumn{2}{|c|}{$\begin{array}{l}\text { Yes } \\
(n=185)\end{array}$} & \multicolumn{2}{|c|}{$\begin{array}{l}\text { No } \\
(n=55)\end{array}$} & & \\
\hline & $\mathrm{n}$ & $\%$ & $\mathrm{n}$ & $\%$ & $\mathrm{n}$ & $\%$ & & & $\mathbf{n}$ & $\%$ & $\mathbf{n}$ & $\%$ & & \\
\hline $\begin{array}{l}\text { Managing body } \\
\text { weight }\end{array}$ & 86 & 35.8 & 29 & 42.0 & 57 & 33.3 & .20 & $\begin{array}{l}1.46 \\
(0.82-2.61)\end{array}$ & 63 & 34.1 & 23 & 41.8 & .06 & $\begin{array}{l}0.53 \\
(0.28-1.03)\end{array}$ \\
\hline $\begin{array}{l}\text { Dealing with side } \\
\text { effects }\end{array}$ & 84 & 35.0 & 26 & 37.7 & 58 & 33.9 & .58 & $\begin{array}{l}1.18 \\
(0.66-2.11)\end{array}$ & 65 & 35.1 & 19 & 34.6 & .51 & $\begin{array}{l}0.80 \\
(0.41-1.56)\end{array}$ \\
\hline $\begin{array}{l}\text { Achieving } \\
\text { exercise goals }\end{array}$ & 81 & 33.8 & 21 & 30.4 & 60 & 35.1 & .50 & $\begin{array}{l}0.81 \\
(0.44-1.50)\end{array}$ & 58 & 31.4 & 23 & 41.8 & .03 & $\begin{array}{l}0.48 \\
(0.28-0.92)\end{array}$ \\
\hline $\begin{array}{l}\text { Psychosocial } \\
\text { health }\end{array}$ & 71 & 29.6 & 19 & 27.5 & 52 & 30.4 & .66 & $\begin{array}{l}0.87 \\
(0.47-1.62)\end{array}$ & 51 & 27.6 & 20 & 36.4 & .12 & $\begin{array}{l}0.58 \\
(0.30-1.14)\end{array}$ \\
\hline Sexual health & 52 & 21.7 & 18 & 26.1 & 34 & 19.9 & .30 & $\begin{array}{l}1.42 \\
(0.74-2.74)\end{array}$ & 40 & 21.6 & 12 & 21.8 & .68 & $\begin{array}{l}0.85 \\
(0.40-1.82)\end{array}$ \\
\hline $\begin{array}{l}\text { Accessing } \\
\text { physician for } \\
\text { examination }\end{array}$ & 35 & 14.6 & 7 & 10.1 & 28 & 16.4 & .23 & $\begin{array}{l}0.58 \\
(0.24-1.39)\end{array}$ & 28 & 15.1 & 7 & 12.7 & .75 & $\begin{array}{l}1.18 \\
(0.46-3.03)\end{array}$ \\
\hline Mammographya & 14 & 6.7 & 6 & 10.3 & 8 & 5.3 & .21 & $\begin{array}{l}2.04 \\
(0.67-6.17)\end{array}$ & 11 & 6.8 & 3 & 6.4 & .85 & $\begin{array}{l}0.88 \\
(0.23-3.34)\end{array}$ \\
\hline
\end{tabular}


How Are Discharged BC Survivors Faring?

\begin{tabular}{|c|c|c|}
\hline \multicolumn{3}{|c|}{$\begin{array}{c}\text { Table } 6 \text { Primary Breast Cancer Survivors" } \\
\text { Predictors of Perceived Need for } \\
\text { Telephone Breast Cancer Survivor- } \\
\text { ship Follow-Up Clinic }(\mathrm{N}=\mathbf{2 4 0})\end{array}$} \\
\hline Predictors & $\begin{array}{l}\text { OR } \\
(95 \% \mathrm{Cl})\end{array}$ & $P$ Value \\
\hline Age at interview ( $\geq 55$ vs $<55$ y) & $0.23(0.11-0.45)$ & $<.0001$ \\
\hline Residence (urban vs nonurban) & $0.49(0.24-0.99)$ & .05 \\
\hline $\begin{array}{l}\text { Endocrine therapy plan (yes vs } \\
\text { no) }\end{array}$ & $0.11(0.03-0.39)$ & .0007 \\
\hline Fatigue (yes vs no) & $2.73(1.39-5.39)$ & .004 \\
\hline Hot flashes (yes vs no) & $0.79(0.39-1.60)$ & .52 \\
\hline Vaginal dryness (yes vs no) & $1.81(0.95-3.45)$ & .07 \\
\hline $\begin{array}{c}\text { Time since diagnosis } \\
12-24 \text { vs }>48 \mathrm{mo} \\
25-36 \text { vs }>48 \mathrm{mo} \\
37-48 \text { vs }>48 \mathrm{mo}\end{array}$ & $\begin{array}{l}1.14(0.23-5.67) \\
1.22(0.49-3.06) \\
1.08(0.46-2.41)\end{array}$ & $\begin{array}{l}.87 \\
.67 \\
.86\end{array}$ \\
\hline Follow-up (cancer center vs PCP) & $0.98(0.46-2.07)$ & .95 \\
\hline
\end{tabular}

Abbreviations: OR, odds ratio; PCP, primary care provider. Logistic regression predicting factors contributing to women's endorsement of their projected use of a telephone survivor followup clinic.

cation from specialist to PCP and to the patient,,$^{53,54}$ the optimal model for return communication from PCP to specialist or patient to specialist is unclear. The National Institute for Clinical Excellence in the United Kingdom recommended indefinite access to a specialized breast care nurse, similar to the concept explored by our study. ${ }^{55}$

A number of studies conclude that nurse-led follow-up meets informational and psychosocial needs, and that telephones are suitable for providing support. ${ }^{40}$ Advantages include the unique clinical and psychosocial knowledge of an oncology nurse, costsavings, convenience, and accessibility. ${ }^{56}$ An upsurge of trials examining nurse-initiated telephone followup support its viability, acceptability, and positive impact on patient lifestyle and QOL. ${ }^{38,39,57-64}$ However, studies have not determined the feasibility and impact of patient-initiated cancer-related follow-up.

Limitations of this study include its crosssectional design, generalizability, reliance on selfreports of examinations, and multiple testing. Because our response rate was low, we advise caution in implementing services based on these results. Strengths include that it provides information missing from the literature. Although the study was cross-sectional, we included women at varying times from diagnosis and found that this factor had no significant effect on perceived need for an HTC. Our sample may overrepresent women attuned to on- going symptoms; however, it was representative of the larger ACR random sample in terms of age and cancer stage, tentatively supporting generalizability. Interviews also followed a structured format likely to reduce response bias. Although we were unable to verify self-reported examination and mammography, we did verify ET adherence, finding that self-report was similar to pharmacy records.

Survivors reported significantly fewer yearly clinical examinations with PCP follow-up. Clear transfer of BC survivorship care to PCPs still resulted in high overall adherence for medical follow-up (85\%$98 \%$ ); however, there is a clear need for improvement. Women also reported high ongoing needs, and most projected that they would use telephone access to specialist care. This was especially true for high-risk groups. Future research and programs could assess and target possible needs by delivering information and support, preventive transition programs, primary care lifestyle interventions, and shared care through lower-cost, nurse-led telephone clinics. Future research should assess, using both quantitative and qualitative methods, the impact of differing telephone clinic models, asking whether contact should be patient-initiated, nurse-initiated, or both.

\section{Acknowledgments}

The authors would like to gratefully thank the women who participated in these interviews.

\section{References}

1. Hewitt M, Greenfield S, Stovall E. From cancer patient to cancer survivor: lost in transition. Washington, DC: The National Academies Press; 2006.

2. Canadian Cancer Statistics 2013. Available at: http://www.cancer.ca/ / media/cancer.ca/cw/publications/canadian \%20 cancer\%20statistics/ canadian-cancer-statistics-2013-en.pdf. Accessed May 20, 2015.

3. American Cancer Society. Cancer Facts \& Figures 2013. Atlanta, GA: American Cancer Society; 2013.

4. Grunfeld E, Dhesy-Thind S, Levine M. Clinical practice guidelines for the care and treatment of breast cancer: follow-up after treatment for breast cancer (summary of the 2005 update). CMAJ 2005;172:1319-1320.

5. Khatcheressian JL, Hurley P, Bantug E, et al. Breast cancer follow-up and management after primary treatment: American Society of Clinical Oncology clinical practice guideline update. J Clin Oncol 2013;31:961965.

6. Gradishar WJ, Anderson BO, Balassanian R, et al. NCCN Clinical Practice Guidelines in Oncology: Breast Cancer. Version 2, 2015. Available at: NCCN.org. Accessed May 20, 2015

7. Denlinger CS, Ligibel JA, Are M, et al. NCCN Clinical Practice Guidelines in Oncology: Survivorship. Version 1, 2015. Available at: NCCN.org. Accessed May 20, 2015.

8. Doyle C, Kushi LH, Byers T, et al. Nutrition and physical activity during and after cancer treatment: an American Cancer Society guide for informed choices. CA Cancer J Clin 2006;56:323-353. 
9. Ballard-Barbash R, Friedenreich CM, Courneya KS, et al. Physical activity, biomarkers, and disease outcomes in cancer survivors: a systematic review. J Natl Cancer Inst 2012;104:815-840.

10. Grunfeld E, Earle CC. The interface between primary and oncology specialty care: treatment through survivorship. J Natl Cancer Inst Monogr 2010;2010:25-30.

11. Jefford M, Rowland J, Grunfeld E, et al. Implementing improved posttreatment care for cancer survivors in England, with reflections from Australia, Canada and the USA. Br J Cancer 2013;108:14-20.

12. McCabe M, Partridge A, Grunfeld E, Hudson M. Risk-based health care, the cancer survivor, the oncologist, and the primary care physician. Semin Oncol 2013;40:804-812.

13. Grunfeld E, Levine MN, Julian JA, et al. Randomized trial of long-term follow-up for early-stage breast cancer: a comparison of family physician versus specialist care. J Clin Oncol 2006;24:848-855.

14. Grunfeld E, Mant D, Yudkin P, et al. Routine follow up of breast cancer in primary care: randomised trial. BMJ 1996;313:665-669.

15. Grunfeld E, Julian JA, Pond G, et al. Evaluating survivorship care plans: results of a randomized clinical trial of patients with breast cancer. J Clin Oncol 2011;29:4755-4762

16. Grunfeld E, Fitzpatrick R, Mant D, et al. Comparison of breast cancer patient satisfaction with follow-up in primary care versus specialist care: results from a randomized controlled trial. Br J Gen Pract 1999;49:705-710.

17. Grunfeld E, Gray A, Mant D, et al. Follow-up of breast cancer in primary care vs specialist care: results of an economic evaluation. Br J Cancer 1999; 79:1227-1233.

18. Lash TL, Fox MP, Buist DS, et al. Mammography surveillance and mortality in older breast cancer survivors. J Clin Oncol 2007;25:3001-3006.

19. Schootman M, Jeffe DB, Lian M, et al. Surveillance mammography and the risk of death among elderly breast cancer patients. Breast Cancer Res Treat. 2008;111:489-496.

20. Paszat L, Sutradhar R, Grunfeld E, et al. Outcomes of surveillance mammography after treatment of primary breast cancer: a populationbased case series. Breast Cancer Res Treat 2009;114:169-178.

21. Geiger AM, Thwin SS, Lash TL, et al. Recurrences and second primary breast cancers in older women with initial early-stage disease. Cancer 2007;109:966-974

22. Yood MU, Owusu C, Buist DS, et al. Mortality impact of less-than-standard therapy in older breast cancer patients. J Am Coll Surg 2008;206:66-75.

23. McCowan C, Shearer J, Donnan PT, et al. Cohort study examining tamoxifen adherence and its relationship to mortality in women with breast cancer. Br Med J 2008;99:1763-1768.

24. Early Breast Cancer Trialists' Collaborative Group. Systemic treatment of early breast cancer by hormonal, cytotoxic, or immune therapy. 133 randomised trials involving 31,000 recurrences and 24,000 deaths among 75,000 women. Lancet 1992;339:1-15.

25. Hershman DL, Shao T, Kushi LH, et al. Early discontinuation and nonadherence to adjuvant hormonal therapy are associated with increased mortality in women with breast cancer. Breast Cancer Res Treat 2011;126:529-537.

26. Varga D, Wischnewsky M, Atassi Z, et al. Does guideline-adherent therapy improve the outcome for early-onset breast cancer patients? Oncology 2010;78:189-195.

27. Chlebowski RT, Geller ML. Adherence to endocrine therapy for breast cancer. Oncology 2006;71:1-9.

28. Murphy CC, Bartholomew LK, Carpentier MY, et al. Adherence to adjuvant hormonal therapy among breast cancer survivors in clinical practice: a systematic review. Breast Cancer Res Treat 2012;134:459-478.

29. Verma S, Madarnas Y, Sehdev S, et al. Patient adherence to aromatase inhibitor treatment in the adjuvant setting. Curr Oncol 2011;18(Suppl 1):S3-9.

30. Cheng KK, Darshini Devi R, Wong WH, Koh C. Perceived symptoms and the supportive care needs of breast cancer survivors six months to five years post-treatment period. Eur J Oncol Nurs 2014;18:3-9.

31. Khan NF, Evans J, Rose PW. A qualitative study of unmet needs and interactions with primary care among cancer survivors. Br J Cancer 2011;105(Suppl 1):S46-51.

32. Urquhart R, Folkes A, Babineau J, Grunfeld E. Views of breast and colorectal cancer survivors on their routine follow-up care. Curr Oncol 2012;19:294-301.

33. Giese-Davis J, Waller A, Carlson LE, et al. Screening for distress, the 6th vital sign: common problems in cancer outpatients over one year in usual care: associations with marital status, sex, and age. BMC Cancer 2012;12:441.
34. Reid-Arndt S, Cox C. Does rurality affect quality of life following treatment for breast cancer? J Rural Health 2010;26:402-405.

35. Friedlander M, Thewes B. Counting the costs of treatment: the reproductive and gynaecological consequences of adjuvant therapy in young women with breast cancer. Intern Med J 2003;33:372-379.

36. Park B, Hwang S. Unmet needs of breast cancer patients relative to survival duration. Yonsei Med J 2012;53:118-125.

37. Thompson J, Coleman R, Colwell B, et al. Preparing breast cancer patients for survivorship (PREP): a pilot study of a patient-centred supportive group visit intervention. Eur J Oncol Nurs 2014;18:10-16.

38. Garrett K, Okuyama S, Jones W, et al. Bridging the transition from cancer patient to survivor: pilot study results of the Cancer Survivor Telephone Education and Personal Support (C-STEPS) program. Patient Educ Couns 2013;92:266-272.

39. Kimman ML, Dirksen CD, Voogd AC, et al. nurse-led telephone follow-up and an educational group programme after breast cancer treatment: results of a 2 × 2 randomised controlled trial. Eur J Cancer 2011;47:1027-1036.

40. Cox K, Wilson E. Follow up for people with cancer: nurse-led services and telephone interventions. J Adv Nurs 2003;43:51-61.

41. Grunfeld E, Hodgson DC, Del Giudice ME, Moineddin R. Population based longitudinal study of follow-up care for breast cancer survivors. J Oncol Pract 2010;6:174-181.

42. Dowsett M, Cuzick J, Ingle J, et al. Meta-analysis of breast cancer outcomes in adjuvant trials of aromatase inhibitors versus tamoxifen. J Clin Oncol 2010;28:509-518.

43. Early Breast Cancer Trialists' Collaborative Group. Effects of chemotherapy and hormonal therapy for early breast cancer on recurrence and 15 year survival: an overview of the randomized trials. Lancet 2005;365:16871717.

44. Early Breast Cancer Trialists' Collaborative Group (EBCTCG), Davies C, Godwin J, et al. Relevance of breast cancer hormone receptors and other factors to the efficacy of adjuvant tamoxifen: patient level metaanalysis of randomized trials. Lancet 2011;378:717-784.

45. Ademuyiwa F, Groman A, Hong CC, et al. Time-trends in survival in young women with breast cancer in a SEER population-based study. Breast Cancer Res Treat 2013;138:241-248.

46. DiMatteo MR, Lepper HS, Croghan TW. Depression is a risk factor for noncompliance with medical treatment: meta-analysis of the effects of anxiety and depression on patient adherence. Arch Intern Med 2000;160:2101-2107

47. Raison CL, Giese-Davis J, Miller AH, Spiegel D. Depression in cancer: mechanisms, consequences and treatment. In: Evans DL, Charney DS, Lewis L, eds. The Physician's Guide to Depression and Bipolar Disorders. New York, NY: McGraw-Hill; 2006:377-410.

48. Madarnas Y, Joy AA, Verma S, et al. Models of care for early-stage breast cancer in Canada. Curr Oncol 2011;18(Suppl 1):S10-19.

49. McCabe MS, Bhatia S, Oeffinger KC, et al. American Society of Clinical Oncology statement: achieving high-quality cancer survivorship care. J Clin Oncol 2013;31:631-640.

50. Mayer EL, Gropper AB, Neville BA, et al. Breast cancer survivors' perceptions of survivorship care options. J Clin Oncol 2012;30:158-163.

51. Del Giudice ME, Grunfeld E, Harvey BJ, et al. Primary care physicians' views of routine follow-up care of cancer survivors. J Clin Oncol 2009;27:3338-3345.

52. Nissen MJ, Beran MS, Lee MW, et al. Views of primary care providers on follow-up care of cancer patients. Fam Med 2007;39:477-482.

53. Stricker C, Jacobs L, Risendal B, et al. Survivorship care planning after the Institute of Medicine recommendations: how are we faring? J Cancer Surviv 2011;5:358-370.

54. Collie K, McCormick J, Waller AE, et al. Qualitative evaluation of care plans for Canadian breast and head-and-neck cancer survivors. Curr Oncol 2014;21:18-28.

55. National Institute for Clinical Excellence. Guidance on Cancer Services Improving outcomes in breast cancer. Manual Update. Available at: http:/ www.nice.org.uk/guidance/csgbc/evidence/improving-outcomes-in-breastcancer-manual-update-2. Accessed May 20, 2015.

56. Kimman ML, Dirksen CD, Voogd AC, et al. Economic evaluation of four follow-up strategies after curative treatment for breast cancer: results of an RCT. Eur J Cancer 2011;47:1175-1185.

57. Beaver K, Campbell M, Williamson S, et al. An exploratory randomized controlled trial comparing telephone and hospital follow-up after treatment for colorectal cancer. Colorectal Dis 2012;14:1201-1209.

58. Leahy M, Krishnasamy M, Herschtal A, et al. Satisfaction with nurse-led telephone follow up for low to intermediate risk prostate cancer patients 
How Are Discharged BC Survivors Faring?

treated with radical radiotherapy. A comparative study. Eur J Oncol Nurs 2013;17:162-169.

59. Marcus AC, Garrett KM, Cella D, et al. Can telephone counseling posttreatment improve psychosocial outcomes among early stage breast cancer survivors? Psychooncology 2010;19:923-932.

60. Sherman DW, Haber J, Hoskins CN, et al. The effects of psychoeducation and telephone counseling on the adjustment of women with early-stage breast cancer. Appl Nurs Res 2012;25:3-16.

61. Pinto BM, Papandonatos GD, Goldstein MG. A randomized trial to promote physical activity among breast cancer patients. Health Psychol 2013;32:616-626.
62. Marcus AC, Diefenbach MA, Stanton AL, et al. Cancer patient and survivor research from the cancer information service research consortium: a preview of three large randomized trials and initial lessons learned. J Health Commun 2013;18:543-562.

63. Hayes SC, Rye S, Disipio T, et al. Exercise for health: a randomized, controlled trial evaluating the impact of a pragmatic, translational exercise intervention on the quality of life, function and treatment-related side effects following breast cancer. Breast Cancer Res Treat 2013;137:175-186.

64. Demark-Wahnefried W, Morey MC, Sloane R, et al. Reach out to enhance wellness home-based diet-exercise intervention promotes reproducible and sustainable long-term improvements in health behaviors, body weight, and physical functioning in older, overweight/obese cancer survivors. J Clin Oncol 2012;30:2354-2361. 


\section{Appendix 1}

\section{Interview Questions}

\section{Introduction}

Hello, is this ?

This is calling from the Cancer Centre with the Virtual Clinic Project. Does this time still work for you? I just want to remind you that all of your answers will be kept confidential. When we analyze our results, answers from many women will be pooled together.

Do you have any questions before we start?

1. (Check - were they sent a letter? If yes then proceed)

2. Do you remember receiving a discharge letter from the Cancer Centre?

3. What was your menopausal status prior to any breast cancer treatment?

4. What was/is your current menopausal status?

\section{Bothersome Symptoms}

The next 10 questions pertain to symptoms that you may or may not be having.

1. Do you experience fatigue?

2. Do you experience insomnia?

3. Do you experience memory loss?

4. Do you experience depression?

5. Do you experience hot flashes?

6. Do you experience lymphedema (swelling of the arm)?

7. Do you experience joint pain?

8. Do you experience numbness/tingling in hands/feet?

9. Do you experience vaginal dryness?

10. Do you experience pain with intercourse?

Do you experience libido (sexual desire)?

Besides what we just discussed, have there been any new medical problems since your breast cancer treatment?

\section{Breast Surgeries}

1. Have you had further breast surgery?

a. Completion mastectomy for prophylaxis or cosmesis

b. Contralateral prophylactic mastectomy

c. Reconstruction

d. Other

2. What type of other breast surgery have you had?

3. Have you required any further surgeries?

4. What type of further surgery have you had?

\section{Hormonal Therapy}

1. Are you taking hormonal therapy?

2. What type of hormone therapy are you taking?

a. Tamoxifen

b. Other

3. (For interviewer to complete) Is this the drug that it was expected the patient would take?

4. If tamoxifen, are you aware of a plan to switch to a different hormonal therapy in the future?

5. Do you recall the date when you picked up your last refill of (hormonal therapy)?

6. Date of pickup (MM/DD/YYYY)? 
7. Where did you obtain your last refill?
a. Cancer Centre pharmacy
b. Other pharmacy
c. Unsure

8. If you are not taking hormone therapy, why not?
a. Never started
b. Stopped because of side effects
c. Stopped for another reason

9. What type of side effect have you had?

10. What was the other reason for stopping your hormone therapy?

11. When did you stop taking hormonal therapy?

12. Have you been started on any new medications (apart from hormonal therapy) since your breast cancer treatment?

13. What type of medication have you started?

\section{Follow-Up Guidelines}

1. Who do you see for breast cancer follow-up?
a. Family doctor
b. Surgeon
c. Still seen at Cancer Centre
d. Other
e. No follow-up with medical doctor

2. Who is the other doctor you see for breast cancer follow-up?

3. How many times per year do you see a doctor for breast cancer follow-up?

4. Have you had a breast/chest/lymph node examination by (health care professional named) within the last year?

5. Do you have breast tissue remaining?

6. Have you had a mammogram since your breast cancer treatment?
a. Yes
b. No
c. Scheduled

7. When is your mammogram scheduled for?

8. How often have you been getting mammograms done?
a. Yearly
b. Other

9. Other: How often have you been getting mammograms done?

10. When was your last mammogram?

11. Where was your last mammogram?

12. Who arranged your last mammogram?
a. Family doctor
b. Surgeon
c. Cancer Centre
d. Other

13. Other: Who arranged your last mammogram?

14. Are you currently postmenopausal?

15. Have you had a bone density test since your breast cancer treatment?

16. How often do you have a bone density test?
a. Yearly
b. Other 
17. Other: How often do you have bone density tests done?

18. When was your last bone density test

19. Where was your last bone density test?

20. Who arranged your last bone density test?
a. Family doctor
b. Surgeon
c. Cancer Centre
d. Other

21. Do you take a calcium supplement on a daily basis most days?

22. What is the total daily dose of your calcium supplement in milligrams?

23. Do you take a vitamin $D$ supplement on a daily basis most days?

24. What is the total daily dose of your vitamin D supplement in milligrams?

\section{Lifestyle Guidelines}

1. What is your current weight in kilograms?

2. Now I will ask you about the time you spend doing moderate exercise and the time you spend doing intense exercise.

a. First, in an average week, how many minutes of moderate exercise do you do?

b. In an average week, how many minutes of intense exercise do you do?

3. How many servings of alcohol do you have on an average week?

\section{Help Beyond That Provided}

I am now going to go through a list of issues that you may or may not have experienced since your breast treatment. I will ask if you have felt like you needed help beyond that provided by your family doctor, surgeon, psychologist, social worker, community resources, or support group with any of the following issues:

1. Did you feel you needed help beyond that provided in managing side effects of breast cancer treatment?

2. Getting in to see a doctor for breast/chest/lymph node examination?

3. Getting mammograms done?

4. Did you feel you needed help beyond that provided in order to get your bone density studies done (if applicable)?

5. Managing body weight?

6. Achieving personal exercise goals?

7. Did you feel you needed help beyond that provided for your psychological health?

8. Sexual health?

\section{Telephone Clinic}

Now I would like for you to think back over time since you finished your treatment. If you had the option to speak on the phone with a medical professional in a breast cancer survivorship clinic, would you have used it?

Do you have any further comments? 
Appendix 2

Discharge Letter Sent to Primary Care Provider (a similar letter with different wording is sent to the patient).

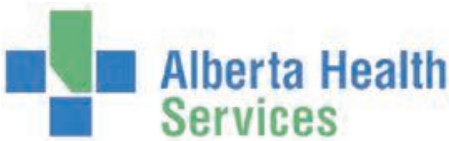

[DATE]

Re: [Patient Name, Date of Birth]

Dear Dr. [Insert Physician Last Name],

Your patient has received treatment(s) for breast cancer at the Cancer Centre and is now being transitioned back to you for ongoing routine breast cancer surveillance in addition to previous standard care, as is concordant with evidence-based literature.

The recommendations outlined below are intended to assist you in providing optimal breast cancer follow-up care for your patient and are not intended to be a substitute for clinical judgment.

\section{SURVEILLANCE for breast cancer recurrence (local, contralateral, or metastatic):}

- Patients may perform self-examination of their breasts and armpits every month.

- Diagnostic mammography should be performed annually. Reconstructed breasts/non-reconstruction post-mastectomy (autologous tissue or implants) do not require any form of imaging surveillance.

- Periodic clinical examination should specifically include examination of the breast(s)/chest wall, supraclavicular and axillary lymph nodes in addition to routine clinical examination. Clinical examinations should be performed every 6 months for 2 years and then annually.

- Other routine surveillance investigations (e.g. lab work, tumour markers, diagnostic imaging) are NOT recommended for asymptomatic patients.

- Patients presenting with any of the following symptoms or signs should undergo the following:

\begin{tabular}{|c|c|}
\hline Symptoms / Signs & Actions / Investigations \\
\hline - new mass in breast & mammography $+/$ - ultrasound (+/- biopsy) \\
\hline - new suspicious rash or nodule on chest wall & refer to surgeon or interventional radiology for biopsy \\
\hline - new palpable lymphadenopathy & refer to surgeon or interventional radiology for biopsy \\
\hline - new persistent bone pain & plain x-ray of affected site(s) and bone scan \\
\hline - new persistent cough or dyspnea & chest $\mathrm{x}$-ray and/or CT chest \\
\hline - new hepatomegaly or RUQ abdominal pain & ultrasound and/or CT scan of abdomen and liver enzymes \\
\hline $\begin{array}{l}\text { - new persistent headache or new concerning } \\
\text { neurologic deficits }\end{array}$ & CT/MRI brain \\
\hline - new onset seizures & seizure management (as required) and CT/MRI brain \\
\hline $\begin{array}{l}\text { - back pain with limb weakness, change in } \\
\text { reflexes, change in sensation, or loss of } \\
\text { bowel/bladder control }\end{array}$ & MRI spine \\
\hline - symptomatic hypercalcemia & iv hydration and bisphosphonate therapy \\
\hline
\end{tabular}

- Patients with confirmed metastatic recurrence should be referred back to the cancer centre. To do so, please contact the Alberta Cancer Line at 1-888-432-8865.

\section{ENDOCRINE THERAPY}

For patients with ER+ breast cancer who have been initiated on adjuvant endocrine therapy (e.g. either single agent or sequential agent - tamoxifen and/or aromatase inhibitor), encourage medication adherence and assess for side effects and complications. You may write refill prescriptions for these medications to be dispensed through the cancer centre pharmacy or fax the prescription to the cancer centre for it to be mailed to the patient.

Typically, endocrine therapy was prescribed for 5 years in total - however selected patients may be offered extended duration of endocrine therapy beyond 5 years. Updated breast cancer treatment guidelines are revised regularly and posted on the Alberta Heath Services - Breast Tumor Group Website (http://www.albertahealthservices.ca/1749.asp). The exact endocrine therapy regimen will be decided in consultation with your patient and communicated to your patient and yourself in separate notation. If you and/or your patient have any questions in this regard, please contact your patient's oncologist for additional clarification. 
Potential side effects or complications:

- Tamoxifen commonly causes hot flashes and (non-bloody) vaginal discharge. It increases the risks for rare complications such as venous thrombotic events, endometrial cancer, cataracts and possibly stroke. Patients with persistent, abnormal vaginal bleeding should be referred to a gynecologist for further evaluation.

- Aromatase inhibitors (i.e., anastrozole, letrozole, exemestane) commonly cause hot flashes, arthralgias, and vaginal dryness. These drugs also increase the risk of osteopenia and/or osteoporosis. Patients currently taking aromatase inhibitors should be monitored with a baseline and regular bone density assessment and treated according to the current Canadian Osteoporosis Guidelines (http://www.osteoporosis.ca/multimedia/guidelines.html).

In patients with a previous history of invasive breast cancer and osteopenia/osteoporosis

- EVISTA ${ }^{\circledR}$ (raloxifene) should NOT be prescribed for management of osteopenia/osteoporosis.

- In cases where osteopenia/osteoporosis treatment is indicated, consideration for an alternate bone targeted agent (e.g. bisphosphonate or RANK-ligand inhibitor) should be used instead.

\section{MONITOR FOR COMPLICATIONS}

\begin{tabular}{lll}
\hline Complication & Treatment-related causes & Actions \\
\hline Fatigue & $\begin{array}{l}\text { - radiation } \\
\text { - chemotherapy }\end{array}$ & $\begin{array}{l}\text { Fatigue should start to improve within months of treatment } \\
\text { completion. Persistent or recurrent fatigue warrants further } \\
\text { work-up to rule out other potential causes. }\end{array}$ \\
\hline Peripheral neuropathy & - taxane-chemotherapy & $\begin{array}{l}\text { Peripheral neuropathy should improve over months. Painful } \\
\text { paresthesias may respond to gabapentin or amitriptyline. }\end{array}$ \\
\hline Lymphedema & $\begin{array}{l}\text { - axillary dissection } \\
\text { - radiation }\end{array}$ & $\begin{array}{l}\text { Early symptoms include arm heaviness or discomfort and may be } \\
\text { present with/without overt swelling. Referral to local rehabilitation } \\
\text { therapy services (e.g. physiotherapy) or tertiary lymphedema } \\
\text { clinic can be made. (TBCC: 403-476-2448); (CCI: 780-432-8710) } \\
\text { If patient is symptomatic or has clinical signs, evaluate further } \\
\text { with ECG and MUGA or echocardiogram and refer to cardiology } \\
\text { if significant abnormalities are noted. }\end{array}$ \\
\hline $\begin{array}{l}\text { Cardiac dysfunction } \\
\text { Myelodysplasia }\end{array}$ & $\begin{array}{l}\text { - anthracycline- } \\
\text { chemotherapy }\end{array}$ & $\begin{array}{l}\text { Perform CBC + differential (with peripheral blood smear) and } \\
\text { refer to hematology if significant persistent cytopenias or blast } \\
\text { cells are noted. }\end{array}$ \\
\hline
\end{tabular}

\section{SUPPORT RESOURCES \& RECOMMENDATIONS}

For your information, the following are support resources and recommendations available for your patients (printed materials may be picked up at their local Cancer Centre).

- General Support Resources:

- AHS - http://www.albertahealthservices.ca

Click: Health Information > Diseases \& Conditions $>$ Cancer

- Canadian Cancer Society - http://www.cancer.ca or 1-888-939-3333

- American Society for Clinical Oncology (patient site) - http://www.cancer.net

- CancerBridges - www. cancerbridges.ca

- Counselling \& Support: Post-treatment adjustment should be assessed. If problems are identified, treat or refer to an appropriately trained professional. Resources are available from the following sources (Community Cancer Centre patients should call the nearest Associate or Tertiary site):

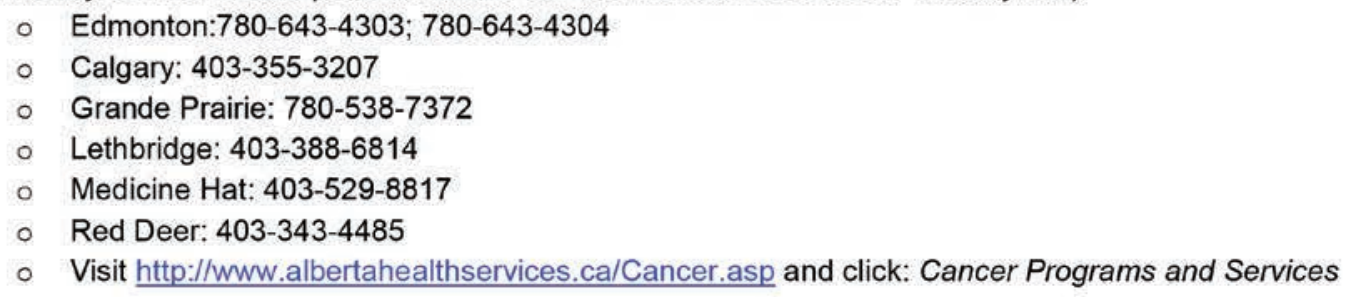


- Sexual Health:

- Menopause Symptoms: Endocrine therapies commonly cause menopausal symptoms and chemotherapy may lead to early menopause. Hot flashes which interfere with sleep and daily function can be managed with non-hormone therapies (e.g. venlafaxine or gabapentin). Vaginal dryness can be managed with a dual purpose vaginal moisturizer and lubricant (eg. Replens). If non-hormonal therapies do not help, vaginal estrogen (Estring, Vagifem) can be considered. Exogenous hormonal therapy is generally contraindicated. For refractory vaginal symptoms, referral to gynecology should be considered.

- Self-Image: For some women, breasts are an important part of their self-image. If they are concerned about how a lumpectomy or mastectomy has changed their body, they may be interested in more information regarding a breast prosthesis or breast reconstruction. Psychological counseling can also be helpful for improving body image satisfaction, addressing relationship concerns and reducing sexual dysfunction.

- Family planning: Pregnancy while on endocrine therapy is contraindicated. The absence of regular menses does not equate to menopause in all cases. Non-hormonal contraception is generally recommended. There is an increased risk of sub-fertility/infertility and premature menopause in women who have had previous chemotherapy.

- Healthy Lifestyle:

Modifiable lifestyle factor Recommendations

Body weight Body mass index (BMI): $18.5-25 \mathrm{~kg} / \mathrm{m}^{2}$

Waist circumference: less than $80 \mathrm{~cm}$ for women and less than $94 \mathrm{~cm}$ for men

Physical activity Be active 2.5 hours/week, focusing on moderate-vigorous activity spread throughout week

Follow cancer prevention recommendations from American Institute for Cancer Research

- Avoid sugary drinks. Limit consumption of energy-dense foods.

Diet

- Eat more of a variety of vegetables, fruits, whole grains and legumes such as beans.

- Limit consumption of red meats (such as beef, pork and lamb) and avoid processed meats.

- Limit consumption of salty foods and foods processed with salt.

Dietary supplements/ Vitamin D: $1000-2000$ IU per day

Bone Health Calcium: $1000-1200 \mathrm{mg}$ per day if postmenopausal (preferably from dietary/food sources)

Alcohol Ideally none or limit consumption ( $<3$ drinks/week)

Smoking Practice smoking cessation. For help contact Alberta Quits 1-877-710-QUIT(7848) or www. albertaquits.ca

At any time if you have any concerns or are in need of more information please call the Alberta Cancer Line: 1-888-432-8865.

We appreciate your partnership in caring for this patient.

Sincerely,

Alberta Breast Cancer Program Team 